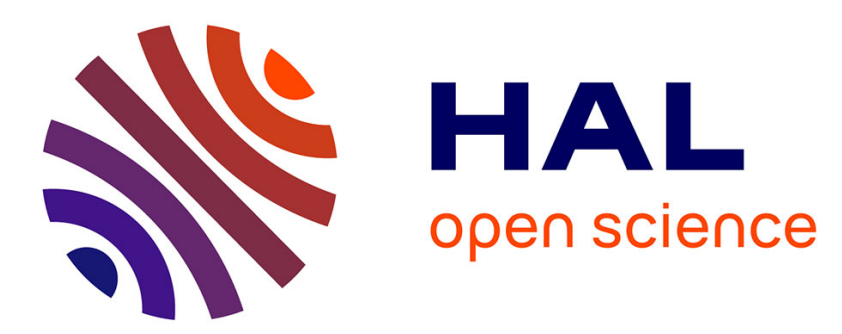

\title{
Relative guidance of aircraft : analysis and comparison of two control approaches
}

\author{
Thierry Miquel, Felix Mora-Camino
}

\section{To cite this version:}

Thierry Miquel, Felix Mora-Camino. Relative guidance of aircraft: analysis and comparison of two control approaches. WAC 2002, SAE World Aviation Congress \& Display, Nov 2002, Phoenix, United States. pp xxxx, 10.4271/2002-01-2922 . hal-00938036

\section{HAL Id: hal-00938036 \\ https://hal-enac.archives-ouvertes.fr/hal-00938036}

Submitted on 11 Jul 2014

HAL is a multi-disciplinary open access archive for the deposit and dissemination of scientific research documents, whether they are published or not. The documents may come from teaching and research institutions in France or abroad, or from public or private research centers.
L'archive ouverte pluridisciplinaire HAL, est destinée au dépôt et à la diffusion de documents scientifiques de niveau recherche, publiés ou non, émanant des établissements d'enseignement et de recherche français ou étrangers, des laboratoires publics ou privés. 


\title{
Relative guidance of aircraft : analysis and comparison of two control approaches
}

\author{
Thierry MIQUEL \\ LAAS du CNRS AND CentRE d'ETUdeS de LA NAVIGATION AERIENNE, TOULOUSE, FRANCE \\ Félix MORA-CAMINo \\ LAAS du CNRS and ECole Nationale de l'AVIATION CIVILE, TOULOUSE, France
}

\begin{abstract}
This paper proposes an analysis and comparison study between two different nonlinear control approaches to design a relative guidance mode for civil aircraft. The first investigated approach is based on feedback linearizing control, whereas the second investigated approach is based on optimal control. These two approaches are compared in terms of performances and complexity, including trajectory characteristics and communication requirements. It appears that both approaches are quite promising and deserve extensive studies for further refinement and validation.
\end{abstract}

\section{INTRODUCTION}

The anticipated traffic increase and future changing needs in air traffic encourages the design of rew strategies to increase air traffic control capacity significantly while at the same time enhancing safety and flight efficiency.

So as to meet this challenge, new concepts such as the delegation to the flight crew of some tasks presently performed by ar traffic controllers have emerged during the last few years [1].

A subset of this delegation concept is related to relative guidance of aircraft. The main challenge for the aircraft relative guidance concept is to enhance air traffic capacity by decreasing air traffic controller workload while at the same time preventing flight crew workload increase. To achieve these goals, new automated functions onboard aircraft must be developed ; indeed, nowadays no automatic control mode is available on-board civil aircraft to perform this task.

The relative guidance concept is supported by the European air traffic control agency. Furthermore, station keeping procedure, which is strongly related to relative guidance of aircraft, is currently investigated in some R\&D European projects [2].

Recent studies have investigated related problems for Unmanned Air Vehicles (UAV) [3] and military aircraft [4]. Nevertheless, research for civil aircraft in this area is in its initial stage : in [2], station keeping is performed manually by the flight deck ; in [5], the authors consider a proportional, integral, and derivative (PID) automatic control system on-board the trailing aircraft that maintains station keeping.

In this context, this paper focuses on the analysis and comparison of two different nonlinear control approaches to design a relative guidance mode for civil aircraft.

The first approach is based on feedback linearizing control. Basically, this technique consists in computing a nonlinear control law that compensates the nonlinearities of the controlled system to enforce linear dynamics to its outputs. The control objective is thus to achieve a convergence maneuver according to predefined dynamics which meet performance requirements.

The second approach is based on optimal control. In this case, a minimum time approach is considered. The proposed design results in a bang-bang suboptimal control through a succession of turns and speed at maximum operational values.

The relative guidance dynamic is confined to the horizontal plane, as it is assumed that the altitude dynamic is controlled by a separate autopilot which is decoupled from the velocity and heading dynamics.

The paper is organized as follows : in the preliminary section, separation objective, reference frame and aircraft model are introduced. This leads to the nonlinear state space representation which is used in this paper. The subsequent sections present the design of the feedback linearizing controller and the design of the suboptimal 
controller. A specific scenario for comparison is then proposed, and results of computer simulations for the two proposed controllers are compared. Finally, conclusions are raised.

\section{PRELIMINARIES}

\section{SEPARATION OBJECTIVE}

The purpose of the separation objective is to indicate to the pilot the required separation between the leading and the trailing aircraft. The limit must be safe but should keep the aircraft close enough so as to provide airspace efficiency.

As some simulations have shown the interest to express in terminal maneuvering area separation objective in terms of delay rather than distance [2], this paper considers a constant time delay separation objective, as introduced in [6]. This specifies a delay between the leading and the trailing aircraft, and the desired position or the trailing aircraft is the position where the leading aircraft was $T_{d}$ seconds earlier. Denoting by $S_{\text {desired }}$ the desired separation, the constant time delay separation objective is related to the speed of the leading aircraft as follows :

$$
S_{\text {desired }}=\int_{t_{0}-T_{d}}^{t_{0}} V_{\text {leader }} \cdot d t
$$

When focusing on sequencing aircraft, as it is the case in this paper, the actual value of the separation between the leading and the trailing aircraft shall converge towards the separation objective.

As current civil aviation regulations [7] set distance separation standard between aircraft, the time delay separation objective must be chosen so that the minimum distance separation standard is not violated.

\section{REFERENCE FRAME}

The purpose of the relative guidance control law is first to direct the trailing aircraft towards the leading aircraft and then to maintain the desired position of the trailing aircraft. In order to design this control law, the equations of relative motion must be established within an appropriate reference frame.

A first candidate is the reference frame affixed to the trailing aircraft position and aligned with the trailing aircraft velocity vector. However, such a reference frame results in a feedback linearizing control law which presents a singular point [3], and non bounded inputs may therefore be required. On the other hand, using a linearized model derived in such a reference frame may result in a control law which is not valid for any initial conditions [8].
In this paper, the reference frame which is used is affixed to the leading aircraft, as shown in the following figure. The 'along track' distance, denoted $\mathrm{TK}(\mathrm{t})$, is aligned with the leading aircraft velocity vector, denoted $V_{L}$, whereas the 'cross track' distance, denoted $\mathrm{XTK}(\mathrm{T})$, is the right handed positive distance between the leading and the trailing aircraft. The heading angle for the trailing aircraft is denoted $\psi$, its speed $V$. Subscribe $L$ is added for all variables related to the leading aircraft.

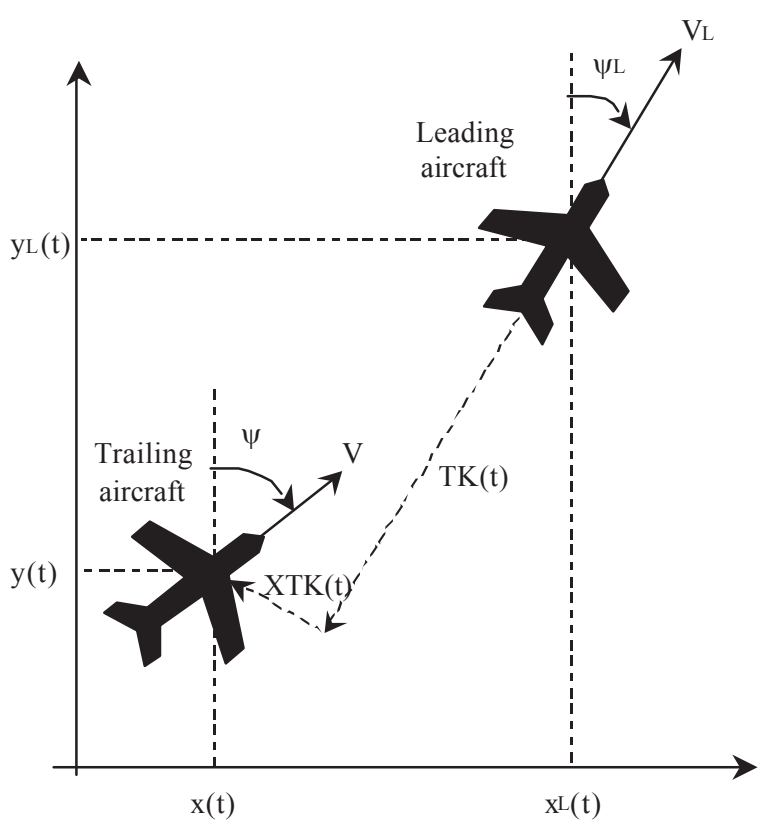

Figure 1 Reference frame affixed to the leading aircraft

From Figure 1, the equations of relative motion between the leading and the trailing aircraft are as follows :

$$
\left\{\begin{array}{l}
\dot{T K}=\dot{\psi}_{L} \cdot X T K+V \cdot \cos \left(\psi_{L}-\psi\right)-V_{L} \\
X \dot{T} K=-\dot{\psi}_{L} \cdot T K+V \cdot \sin \left(\psi_{L}-\psi\right)
\end{array}\right.
$$

\section{AIRCRAFT MODEL}

A fully co-ordinated (i.e. side-slip angle is assumed to be zero) aircraft, flying over a flat, non rotating earth, within a standard atmosphere with no wind is considered.

As in many modern jets, it is assumed that the control channels of the trailing aircraft are able to operate in a decoupled fashion :

- The flight path angle $\gamma$, thanks to an altitude hold function of the longitudinal autopilot. In this paper, as far as the movement in the vertical plane is not considered, an altitude hold autopilot model is not relevant. 
- The speed of the aircraft, thanks to an airspeed hold autopilot. An approximation of this function used in this paper is a first order model, where $V_{c}$ is the commanded speed, $V$ the actual speed and $\tau_{\mathrm{V}}$ a time constant :

$$
\dot{V}=\frac{V_{c}-V}{\tau_{V}}
$$

- The bank angle $\varphi$, thanks to an heading hold function of the lateral autopilot; for small bank angle and loading factors, the following relationship between heading rate and bank angle is assumed, where $\mathrm{g}$ is the acceleration of gravitation, $\varphi_{c}$ the commanded bank angle and $\mathrm{V}$ the actual speed :

$$
\dot{\psi}=\frac{g \cdot \varphi_{c}}{V}
$$

A more realistic model for the heading dynamic would have been obtained by considering that the bank angle is driven by a first order model of the following form, where $\varphi$ is the actual bank angle and $\tau_{\varphi}$ a time constant :

$$
\dot{\varphi}=\frac{\varphi_{c}-\varphi}{\tau_{\varphi}}
$$

For civil aircraft, the time constant $\tau_{\varphi}$ is small enough compared to the time constant $\tau_{\mathrm{V}}$. Furthermore, this first order model introduces more difficulties when designing the control law than it improves its performance. Therefore, it is removed for the purpose of designing the control law. Nevertheless, it is taken into account within simulations.

\section{NONLINEAR STATE SPACE REPRESENTATION}

With the notations shown in Figure 1, the dynamic of the trailing aircraft is as follows :

$$
\left\{\begin{array}{l}
\dot{x}=V \cdot \sin (\psi) \\
\dot{y}=V \cdot \cos (\psi)
\end{array}\right.
$$

Furthermore, the 'along track' distance, denoted TK, and the 'cross track' distance, denoted XTK, are expressed as follows :

$$
\left\{\begin{array}{l}
T K=\left(x-x_{L}\right) \cdot \sin \left(\psi_{L}\right)+\left(y-y_{L}\right) \cdot \cos \left(\psi_{L}\right) \\
X T K=\left(x-x_{L}\right) \cdot \cos \left(\psi_{L}\right)-\left(y-y_{L}\right) \cdot \sin \left(\psi_{L}\right)
\end{array}\right.
$$

Finally, a nonlinear state space representation of the relative motion is obtained by gathering ( 3 ), ( 4 ), ( 6 ) and ( 7 ). The positions ( $x_{\mathrm{L}}$ and $\mathrm{y}$ ), heading $\left(\psi_{\mathrm{L}}\right)$ and velocity $\left(V_{L}\right)$ of the leading aircraft are declared exogenous parameters. This leads to a fourth order representation, which is affine with regard to the input variables, $\underline{u}$ :

$$
\left\{\begin{array}{l}
\underline{\dot{x}}=F(\underline{x})+G(\underline{x}) \cdot \underline{u} \\
\underline{y}=H(\underline{x})
\end{array}\right.
$$

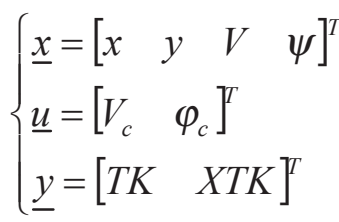

$$
F(\underline{x})=\left[\begin{array}{c}
V \cdot \sin (\psi) \\
V \cdot \cos (\psi) \\
-V / \tau_{V} \\
0
\end{array}\right]
$$

$$
G(\underline{x})=\left[\begin{array}{cc}
0 & 0 \\
0 & 0 \\
V_{c} / \tau_{V} & 0 \\
0 & g / V
\end{array}\right]
$$

$$
H(\underline{x})=\left[\begin{array}{l}
\left(x-x_{L}\right) \cdot \sin \left(\psi_{L}\right)+\left(y-y_{L}\right) \cdot \cos \left(\psi_{L}\right) \\
\left(x-x_{L}\right) \cdot \cos \left(\psi_{L}\right)-\left(y-y_{L}\right) \cdot \sin \left(\psi_{L}\right)
\end{array}\right]
$$

\section{CONTROL SCHEME}

The resulting control scheme is presented hereafter :

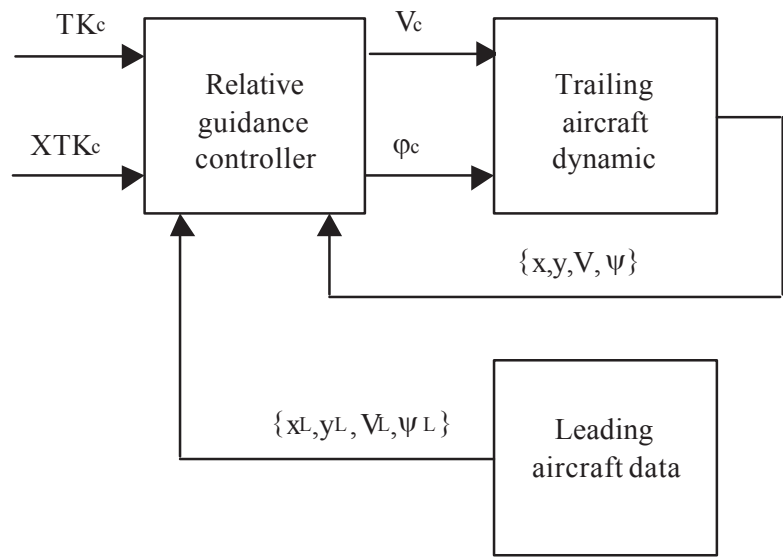

Figure 2 Block diagram of the relative guidance control system

The trailing aircraft dynamic corresponds to the nonlinear state space representation presented in the previous subsection. 
With respect to communication perspectives, the leading aircraft is supposed to broadcast every second the following data :

- $\mathrm{x}_{\mathrm{L}}$ and $\mathrm{y}_{\mathrm{L}}$ positions,

- $\quad$ True airspeed, $\mathrm{V}_{\mathrm{L}}$,

- Heading, $\psi_{\mathrm{L}}$.

The purpose of the following sections is to focus on the design of the relative guidance controller, either by feedback linearizing control or by optimal control.

\section{FEEDBACK LINEARIZING CONTROLLER}

This technique [9] consists in computing a control law that compensates the nonlinearities of the system to enforce linear dynamics to its outputs. A relative degree is determined from the affine representation for each output variable : this relative degree fixes the order which can be assigned to the output dynamics.

From now, it is assumed that heading and velocity of the leading aircraft remain constant.

When time differencing twice the equations of system ( 12 ), and keeping in mind the previous assumptions, the outputs obey to the following equations :

$$
\left[\begin{array}{c}
\ddot{T K} \\
X \ddot{T K}
\end{array}\right]=\Delta_{0}(\underline{x})+\Delta(\underline{x}) \cdot\left[\begin{array}{l}
V_{c} \\
\varphi_{c}
\end{array}\right]
$$

Where :

$$
\begin{gathered}
\Delta(\underline{x})=\left[\begin{array}{cc}
\cos \left(\psi-\psi_{L}\right) / \tau_{V} & -g \cdot \sin \left(\psi-\psi_{L}\right) \\
\sin \left(\psi-\psi_{L}\right) / \tau_{V} & g \cdot \cos \left(\psi-\psi_{L}\right)
\end{array}\right] \\
\Delta_{0}(\underline{x})=\left[\begin{array}{l}
-V \cdot \cos \left(\psi-\psi_{L}\right) / \tau_{V} \\
-V \cdot \sin \left(\psi-\psi_{L}\right) / \tau_{V}
\end{array}\right]
\end{gathered}
$$

As the rank of the matrix $\Delta(\underline{x})$ is always 2 and presents no singularity in the state space, there is no inner dynamic. So the parameters of the output dynamics can be chosen without damage for the overall stability of the system. Inverting ( 13 ) leads to the following general non linear control law:

$$
\left[\begin{array}{c}
V_{c} \\
\varphi_{c}
\end{array}\right]=\Delta(\underline{x})^{-1} \cdot\left[\begin{array}{c}
f_{1}(T K, \dot{T K}) \\
f_{2}(X T K, X \dot{T} K)
\end{array}\right]+\left[\begin{array}{l}
V \\
0
\end{array}\right]
$$

$$
\Delta(\underline{x})^{-1}=\left[\begin{array}{cc}
\tau_{V} \cdot \cos \left(\psi-\psi_{L}\right) & \tau_{V} \cdot \sin \left(\psi-\psi_{L}\right) \\
-\sin \left(\psi-\psi_{L}\right) / g & \cos \left(\psi-\psi_{L}\right) / g
\end{array}\right]
$$

The functions $f_{1}($.$) and f_{2}($.$) are chosen so that the required$ dynamic performances (i.e. stability, overshoot) are met :

$$
\left\{\begin{array}{l}
f_{1}(T K, T K)=-2 \cdot w_{1} \cdot T K-w_{1}^{2} \cdot T K \\
f_{2}(X T K, X \dot{T} K)=-2 \cdot w_{2} \cdot X \dot{T} K-w_{2}^{2} \cdot X T K
\end{array}\right.
$$

In the previous equations, the damping ratios have been set to 1 . The natural frequencies $w_{1}$ and $w_{2}$ have to be chosen in order to ensure satisfactory performances with respect to transient response.

The motivation to set the damping ratios to 1 is to ensure no overshoot of the 'along track' and 'cross track' distances, $\mathrm{TK}(\mathrm{t})$ and $\mathrm{XTK}(\mathrm{t})$ respectively. They are then bounded by their initial values, $\mathrm{TK}_{0}$ and $\mathrm{XTK}_{0}$ respectively, and their final values, i.e. zero. This is illustrated in the following figure :

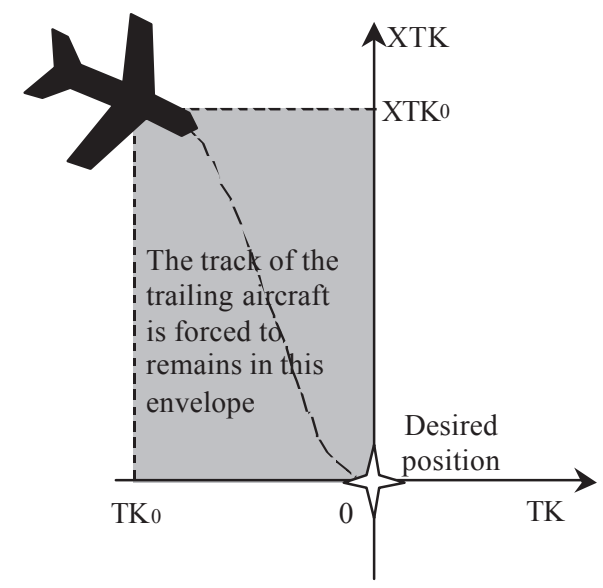

Figure 3 Track envelope of the trailing aircraft

From an operational point of view, this feature may help the pilot and/or the air traffic controller to detect any abnormal situation : any overshoot may indicate a failure which, if confirmed, is followed by an emergency procedure (e.g. switch off the relative guidance mode, and take back the aircraft commands). 


\section{SUBOPTIMAL CONTROLLER}

\section{FORMULATION OF THE OPTIMAL GUIDANCE PROBLEM}

In this section, the idea is to design an alternative control law using optimal control theory [10]. The optimization problem is to find the control input $\underline{\underline{u}}=\left[\mathrm{V}_{\mathrm{c}}, \varphi_{\mathrm{c}}\right]^{\top}$ which drives the system defined by ( 2 ), ( 3 ) and ( 4 ) from a given initial condition to a required target point while minimizing the transition time $\mathrm{T}$. The solution of this problem shall obey to the following constraints :

- Control constraints :

$$
\left\{\begin{array}{l}
-\varphi_{\max } \leq \varphi \leq+\varphi_{\max } \\
V_{\min } \leq V \leq V_{\max }
\end{array}\right.
$$

- Initial conditions :

$$
\left\{\begin{array}{l}
T K(0)=T K_{0} \\
X T K(0)=X T K_{0} \\
V(0)=V_{0} \\
\psi(0)=\psi_{0}
\end{array}\right.
$$

- $\quad$ Required target point :

$$
\left\{\begin{array}{l}
\operatorname{TK}(T)=0 \\
X T K(T)=0 \\
V(T)=V_{L} \\
\psi(T)=\psi_{L}
\end{array}\right.
$$

It appears easily that the global solution of this problem is very difficult to characterize. This intricacy can be overcome by breaking up this problem into a 'cross track' and an 'along track' subproblem. This results in suboptimal but simpler control laws.

\section{'CROSS TRACK' SUBOPTIMAL CONTROL LAW}

The 'cross track' suboptimal control law has been derived by assuming a constant velocity of the trailing aircraft. The relevant equations of motion are :

$$
\left\{\begin{array}{l}
X \dot{T} K=V \cdot \sin \left(\psi-\psi_{L}\right) \\
\dot{\psi}=\frac{g \cdot \varphi_{c}}{V}
\end{array}\right.
$$

The subproblem reduces to find the bank angle time history, $\varphi_{c}$, that satisfies the necessary conditions of the minimum principle and transfers the initial state to the desired final state.
For the case at hand, the Hamiltonian is :

$$
\begin{aligned}
H & =\min _{u}\{1 \\
& \left.+\lambda_{X T K} \cdot V \cdot \sin \left(\psi-\psi_{L}\right)+\lambda_{\psi} \cdot \frac{g \cdot \varphi_{c}}{V}\right\}
\end{aligned}
$$

Minimization over $\varphi_{c}$ in ( 23 ) under bank angle control constraints ( 19 ) yields :

$$
\varphi_{c}^{*}=-\varphi_{\max } \cdot \operatorname{sgn}\left(\lambda_{\psi}\right)
$$

This bang-bang control law has already been discussed in [11] and [12]. As underlined in those references, this problem is not 'normal', i.e. it may exist singular optimum control, $\varphi_{c}{ }^{*}=0$, which occurs whenever $\lambda_{\psi}$ is identically zero over a nonzero time interval. Thus, it follows that an optimum trajectory consists of turns with maximum bank angle over nonsingular intervals, and straight line flight over singular intervals.

As the order of this problem is 2 , there is no need to characterize the co-state variables $\lambda_{\mathrm{XTK}}$ and $\lambda_{\mu}$. Indeed, the phase portraits of nonsingular optimal trajectories in the state space coordinates are obtained by the elimination of time in ( 22 ):

$$
\frac{g \cdot \varphi_{c}^{*}}{V} \cdot \mathrm{dXTK}=V \cdot \sin \left(\psi-\psi_{L}\right) \cdot d \psi
$$

Parameters $\mathrm{V}, \psi_{\mathrm{L}}$ and $\varphi_{\mathrm{c}}{ }^{*}$ being taken as constants, the solution of ( 25 ) satisfying the final state conditions ( 21 ) is the following switching curve :

$$
X T K=\frac{V^{2}}{g \cdot \varphi_{c}^{*}} \cdot\left(1-\cos \left(\psi-\psi_{L}\right)\right)
$$

Figure 4 illustrates an optimal trajectory in the state space coordinates; the solid lines indicates the switching curves and the arrows give the direction of motion along the segments : 


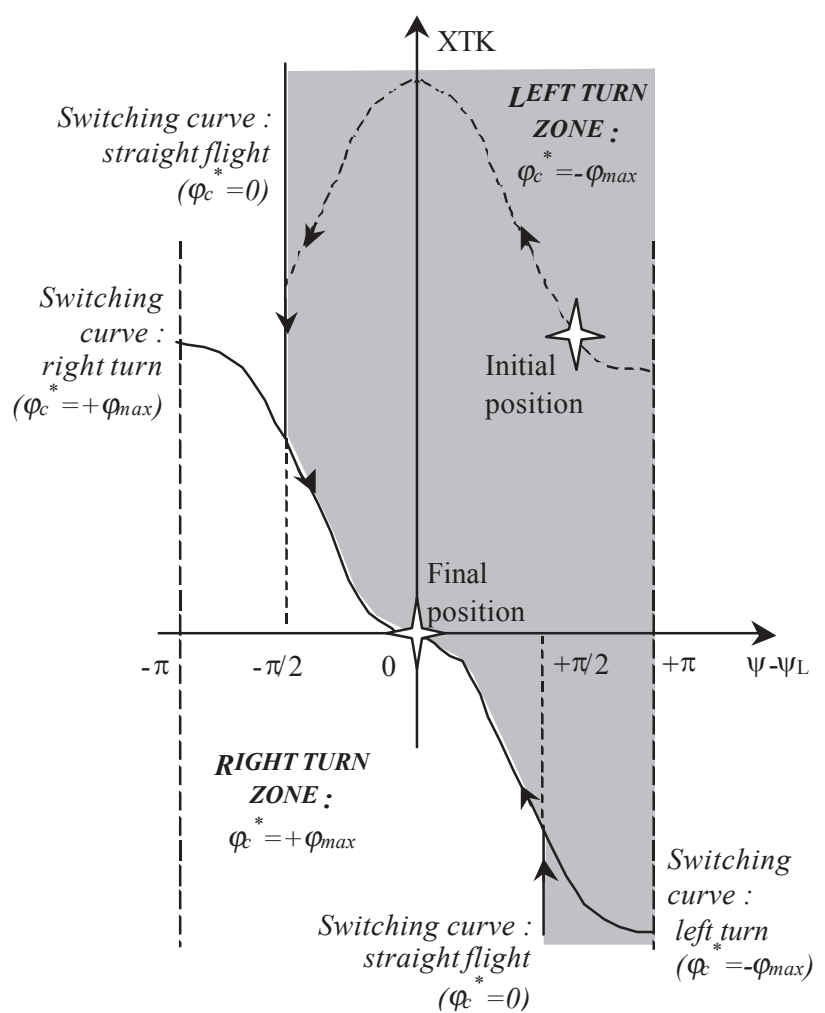

Figure 4 'cross track' suboptimal control law

From an operational pint of view, the preceding figure means a convergence at right angle to the desired track (indeed, the straight flight switching curve is at $\left(\psi-\psi_{\mathrm{L}}\right)= \pm \pi / 2$, which from $(22)$ corresponds to $\left.\mathrm{dXTK} / \mathrm{dt}=0\right)$. Thus the visual acquisition of the leading aircraft by the pilots of the trailing aircraft may be quite difficult. Moreover, this control law minimizes the merging time to the leading aircraft track to the detriment of the time to achieve the desired 'along track' distance. Therefore, the preceding figure has been modified in order to decrease the convergence angle $\left(\psi-\psi_{\llcorner}\right)$: the chosen value is $\pm \pi / 4$, which allows the maximum value of $d T K / d t+d X T K / d t$ :

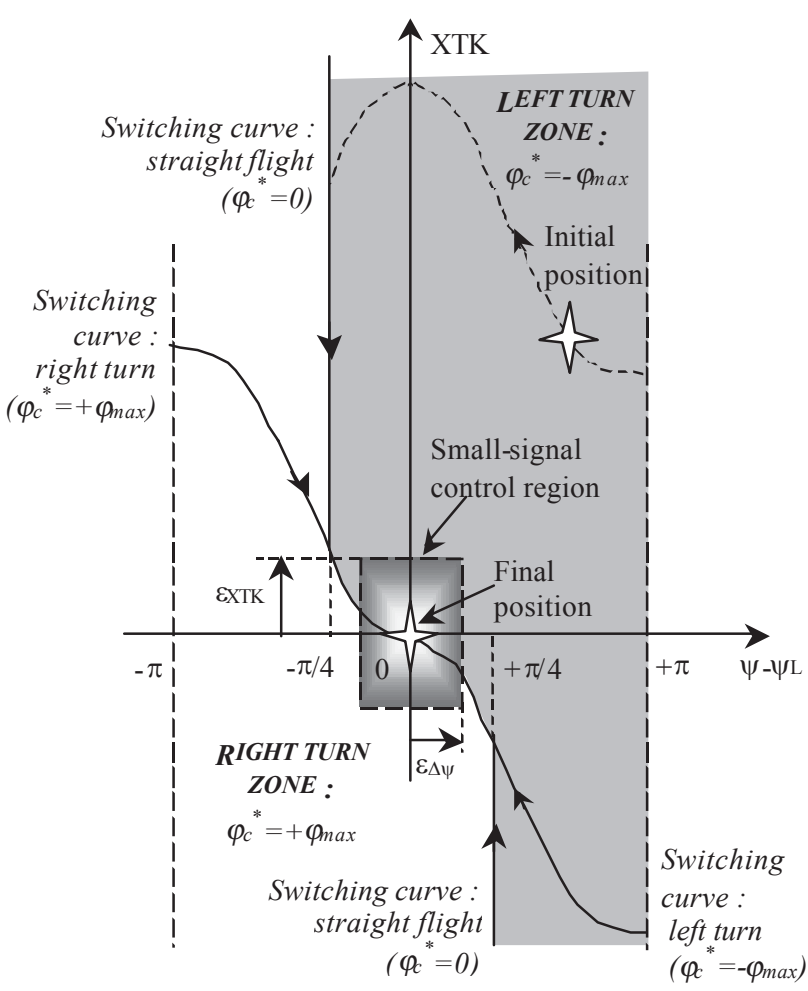

Figure 5 Modified 'cross track' suboptimal control law

The preceding figure can be easily translated into the following feedback control law algorithm :

- if the initial state lies on the switching curves, then the bank angle control follows them (i.e. the bank angle is $-\varphi_{\max },+\varphi_{\max }$ or 0$)$;

- if, as in most cases, the initial state is not on a switching curve, then the bank angle control must be chosen to move the system toward the switching curves : in the left turn zone, the bank angle control is $-\varphi_{\max }$ whereas in the right turn zone, the bank angle control is $+\varphi_{\max }$

In addition, in order to avoid the tendency of the system to zigzag near the final position, where the controlled bank angle chatters back and forth rather than being set to zero, a small-signal control region $\left.\xi_{\Delta \Psi}, \varepsilon_{X T K}\right)$ has been defined where the control law is as follows:

$$
\varphi_{c}^{*}=-\frac{\varphi_{\max }}{2} \cdot\left(\frac{\psi-\psi_{L}}{\varepsilon_{\Delta \psi}}+\frac{X T K}{\varepsilon_{X T K}}\right)
$$




\section{'ALONG TRACK' SUBOPTIMAL CONTROL LAW}

The 'along track' suboptimal control law has been derived by assuming a constant heading of the trailing aircraft. The relevant equations of motion are :

$$
\left\{\begin{array}{l}
\dot{T K}=V \cdot \cos \left(\psi-\psi_{L}\right)-V_{L} \\
\dot{V}=\frac{V_{c}-V}{\tau_{V}}
\end{array}\right.
$$

For this case, the Hamiltonian is :

$$
\begin{aligned}
H & =\min _{u}\{1 \\
& \left.+\lambda_{T K} \cdot\left(V \cdot \cos \left(\psi-\psi_{L}\right)-V_{L}\right)+\lambda_{V} \cdot \frac{V_{c}-V}{\tau_{V}}\right\}
\end{aligned}
$$

$\mathrm{H}$ is minimized over $\mathrm{V}_{\mathrm{c}}$ under speed control constraints ( 19 ). This yields to the following control law, which has no singularity :

$$
V_{c}^{*}=\left(\frac{V_{\min }-V_{\max }}{2}\right) \cdot \operatorname{sgn}\left(\lambda_{V}\right)+\left(\frac{V_{\min }+V_{\max }}{2}\right)
$$

The phase portraits of optimal trajectories in the state space coordinates are obtained by the elimination of time in ( 28$)$ :

$$
\frac{V_{c}^{*}-V}{\tau_{V}} \cdot \mathrm{dTK}=\left(V \cdot \cos \left(\psi-\psi_{L}\right)-V_{L}\right) \cdot d V
$$

Parameters $\psi, \quad \psi_{\mathrm{L}}, \mathrm{V}_{\mathrm{L}}$ and $\mathrm{V}_{\mathrm{c}}{ }^{*}$ are being taken as constants. Then, the solution of ( 31 ) satisfying the final state conditions ( 21 ) is associated to the following switching curve :

$$
\begin{aligned}
& \frac{T K}{\tau_{V}}=V_{L}-V \cdot \cos \left(\psi-\psi_{L}\right)+\ln \left(\frac{\left|V_{c}^{*}-V\right|^{\alpha}}{\left|V_{c}^{*}-V_{L}\right|^{\beta}}\right) \\
& \left\{\begin{array}{l}
\alpha=V_{L}-V_{c}^{*} \cdot \cos \left(\psi-\psi_{L}\right) \\
\beta=V_{L}-V_{c}^{*}
\end{array}\right.
\end{aligned}
$$

Figure 6 illustrates an optimal trajectory in the state space coordinates; the solid lines indicates the switching curves for the specific case where $\psi=\psi_{L}$, and the arrows give the direction of motion along the segments. As in the previous case, the motivation to introduce the small-signal control region $\left(\varepsilon_{\Delta V}, \varepsilon_{T K}\right)$ is to avoid the tendency of the system to zigzag near the final position :

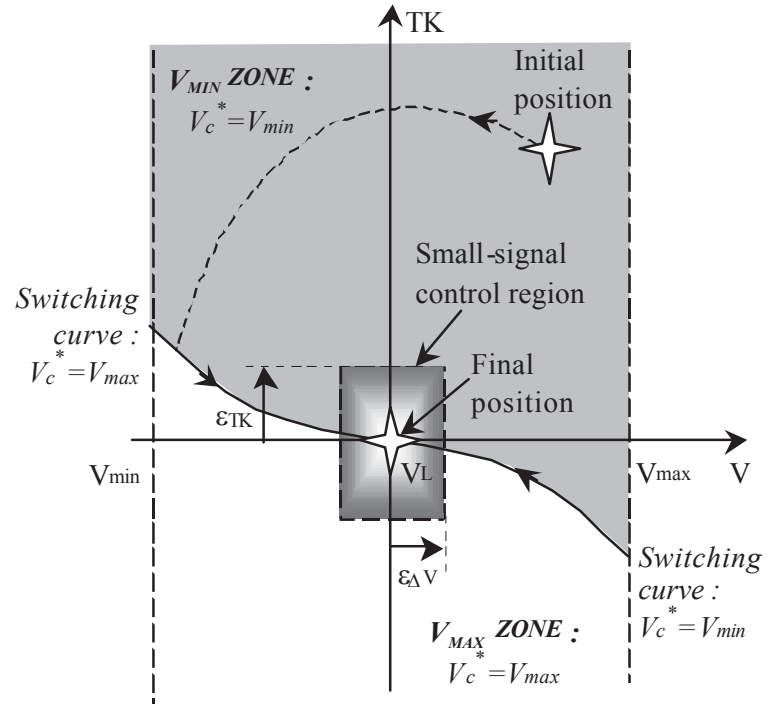

Figure 6 'along track' suboptimal control law

As in the previous case, the preceding figure can be easily translated into a feedback control law algorithm.

\section{SCENARIO}

In this section a scenario is designed in order to evaluate the properties of the control laws previously described.

The leading aircraft starts at $x_{0}=0 \mathrm{NM}, \mathrm{y}_{0}=0 \mathrm{NM}$, with initial true airspeed and heading of $240 \mathrm{kts}$ and 90 degrees respectively. No wind is assumed during the simulation.

The bank angle command of the leading aircraft is always zero, except between $600 \mathrm{sec} \leq \mathrm{t} \leq 630 \mathrm{sec}$ where the bank angle command is set to 20 degrees : this leads to a heading change of +60 degrees.

The true airspeed command is first held at $240 \mathrm{kts}$ for $\mathrm{t} \leq$ $300 \mathrm{sec}$, then it is set to $190 \mathrm{kts}$.

The trailing aircraft starts at $x_{0}=-10 \mathrm{NM}, \mathrm{y}_{0}=+5 \mathrm{NM}$, with initial true airspeed and heading of $240 \mathrm{kts}$ and 90 degrees respectively.

The simulation period lasts $15 \mathrm{~min}$ (900 sec), and the requested separation is a constant time delay of $90 \mathrm{sec}$.

The true airspeed and bank angle constraints are as follows :

$$
\begin{gathered}
\left\{\begin{array}{l}
V_{\min }=170 \mathrm{kts} \\
V_{\max }=300 \mathrm{kts}
\end{array}\right. \\
\left\{\begin{array}{l}
\varphi_{\min }=-30 \mathrm{deg} . \\
\varphi_{\max }=+30 \mathrm{deg} .
\end{array}\right.
\end{gathered}
$$


Those values may correspond to hose of a jet aircraft following an approach procedure around flight level 60 .

The time constant $\tau_{V}$ of the airspeed hold autopilot $(3)$ is set at a value which enable the aircraft to decelerate from $300 \mathrm{kts}$ to $170 \mathrm{kts}$ in about $3 \mathrm{~min}$ :

$$
\tau_{V}=40 \mathrm{sec}
$$

The time constant $\tau_{\varphi}$ of the heading hold autopilot ( 5 ) is set at a value which enable the aircraft to bank from 0 to 30 degrees in about $3 \mathrm{sec}$ :

$$
\tau_{V}=1 \text { sec }
$$

As the leading aircraft is supposed to broadcast its data every second (see subsection CONTROL SCHEME), the control inputs $V_{c}$ and $\varphi_{c}$ are computed with the same rate. Nevertheless, the state vector of the leading aircraft is sampled every $100 \mathrm{~ms}$.

For the linearizing controller, the natural frequencies $w_{4}$ and $w_{2}$ have been set in order that speed and bank angle do not exceed the previous limitations :

$$
\left\{\begin{array}{l}
w_{1}=1 / 900 \mathrm{sec}^{-1} \\
w_{2}=1 / 300 \mathrm{sec}^{-1}
\end{array}\right.
$$

For the suboptimal controller, the parameters of the smallsignal control region have been chosen as follows :

$$
\begin{aligned}
& \left\{\begin{array}{l}
\varepsilon_{\Delta \psi}=5 \mathrm{deg} . \\
\varepsilon_{X T K}=0.2 \mathrm{NM}
\end{array}\right. \\
& \left\{\begin{array}{l}
\varepsilon_{\Delta V}=2 \mathrm{kts} \\
\varepsilon_{T K}=0.2 \mathrm{NM}
\end{array}\right.
\end{aligned}
$$

\section{RESULTS AND COMPARISON}

MOVEMENT OF THE TRAILING AIRCRAFT IN THE HORIZONTAL PLANE

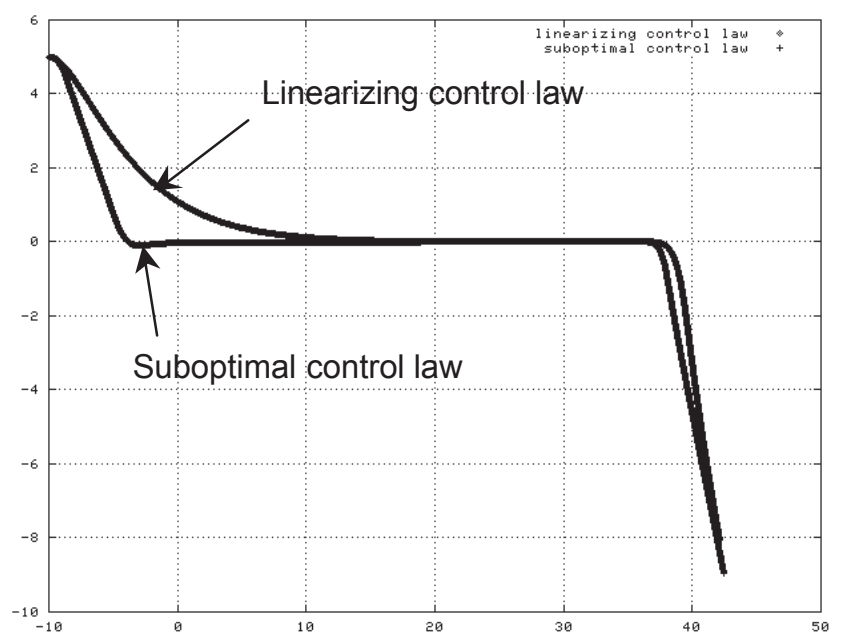

Figure 7 Movement of the trailing aircraft in the horizontal plane (axes in NM)

As designed, the suboptimal control law enforces the leading aircraft to merge towards the leading aircraft track with a 45 degrees convergence angle. Nevertheless, a slight overshoot appears near the end of the merging phase. On the other hand, the linearizing control law is longer to merge towards the leading aircraft track, and induces a small overshoot to follow the leading aircraft track when it turns.

\section{'ALONG TRACK' AND 'CROSS TRACK' DISTANCES BETWEEN THE LEADING AND THE TRAILING AIRCRAFT}

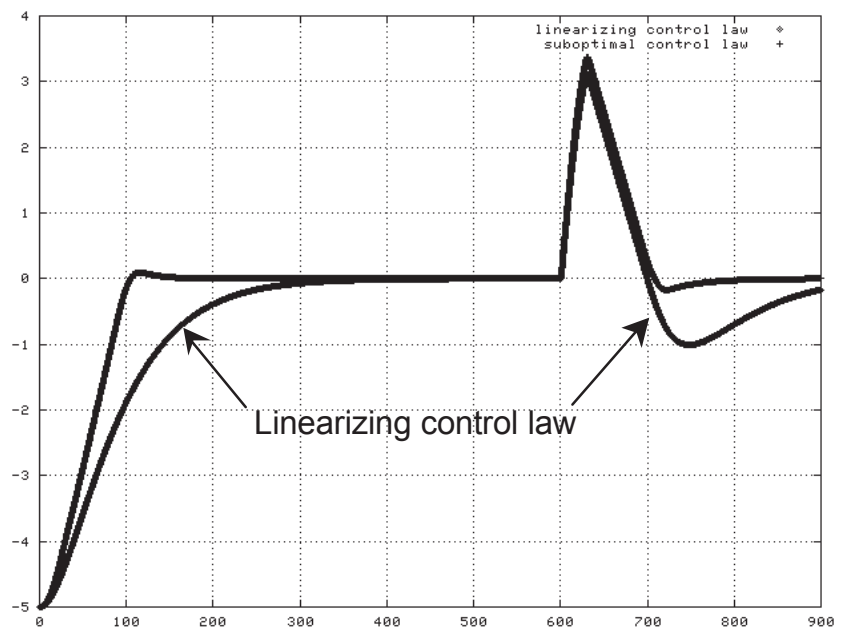

Figure 8 'Cross track' distance (XTK, in NM) between the leading and the trailing aircraft as a function of time (in sec) 


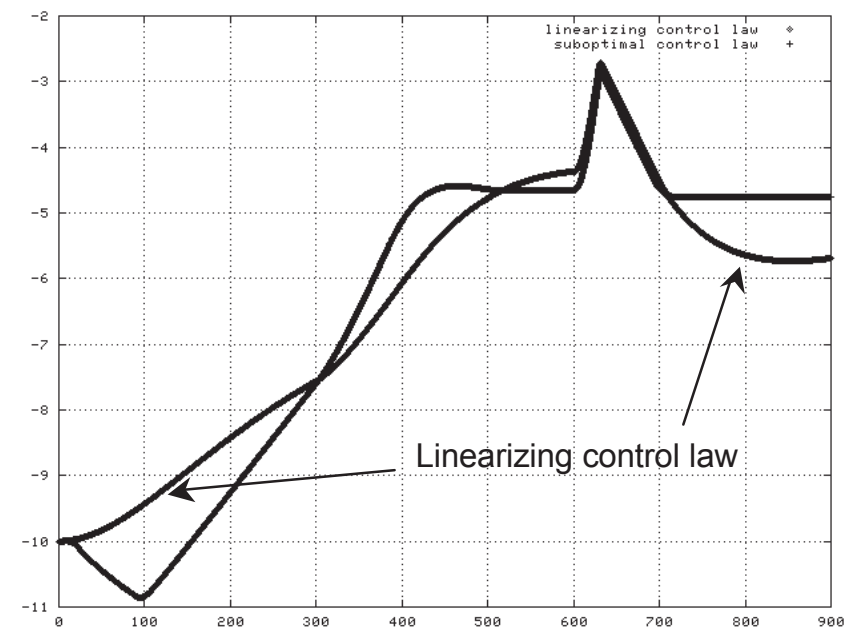

Figure 9 'Along track' distance (TK, in NM) between the leading and the trailing aircraft as a function of time (in sec)

The maximum values of the 'along track' and 'cross track' distances are quite similar whatever the control law. Nevertheless Figure 9 shows that the stationary state is not achieved in the simulation duration when the linearizing control law is used.

\section{SLANT RANGE BETWEEN THE LEADING AND THE TRAILING AIRCRAFT}

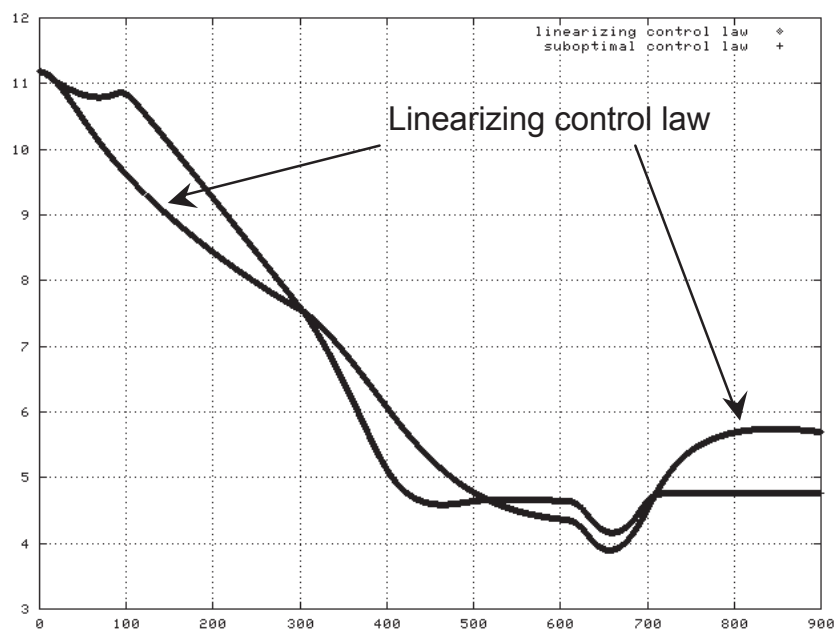

Figure 10 Slant range (in NM) between the leading and the trailing aircraft as a function of time (in sec)

The stationary slant range is $4.75 \mathrm{NM}$, i.e. $190 \mathrm{kts} \times 90 \mathrm{sec}$ which is achieved after about $700 \mathrm{sec}(\sim 12 \mathrm{~min})$ by the suboptimal control law. Nevertheless, the minimum value of the slant range (4.16 NM for the suboptimal control law, 3.89 NM for the linearizing control law) is under the stationary value : this is due to the turn of the leading aircraft.
COMMANDED AND ACTUAL SPEED OF THE LEADING AND TRAILING AIRCRAFT

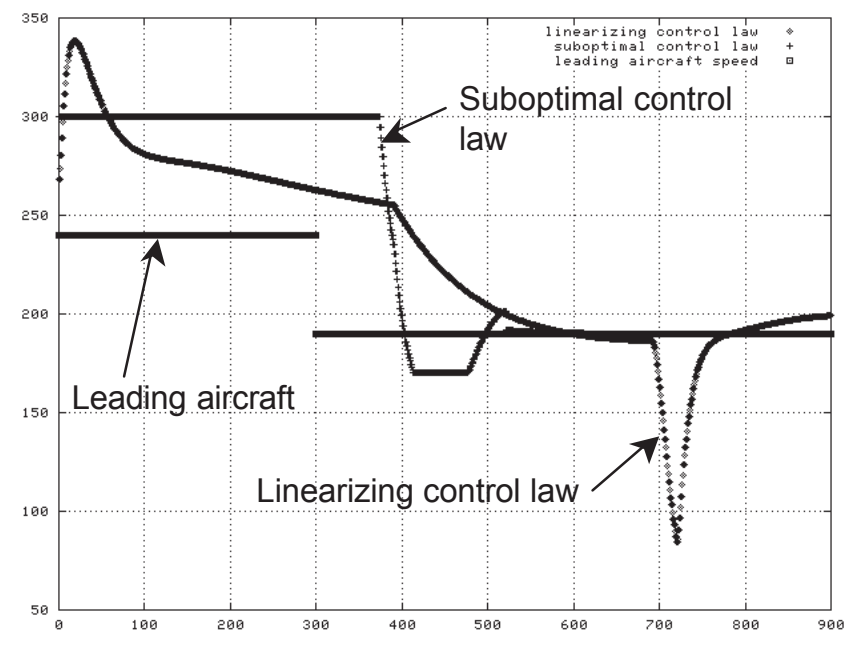

Figure 11 Commanded speed (in kts) as a function of time (in sec)

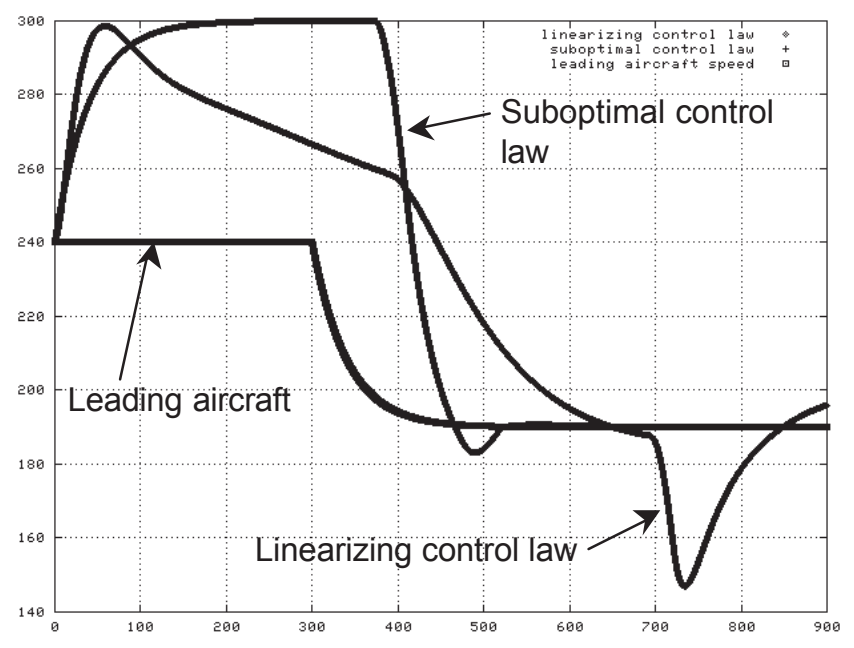

Figure 12 Actual speed (in kts) as a function of time (in sec)

The previous figures shows the difficulty to settle the degrees of freedom of the linearizing control law (i.e. the natural frequencies $w_{1}$ and $w_{2}$ ) : indeed, the values have been set in order that the maximum actual value do not exceed the maximum available speed (i.e. $300 \mathrm{kts}$ ), but the minimum actual value is out of control in this example. This leads to a minimum speed less than $150 \mathrm{kts}$, whereas the current limitation is $170 \mathrm{kts}$. Such difficulties do not appear in the suboptimal control law since such constraints are taken into account in the design process. 
COMMANDED AND ACTUAL BANK ANGLE OF THE LEADING AND TRAILING AIRCRAFT

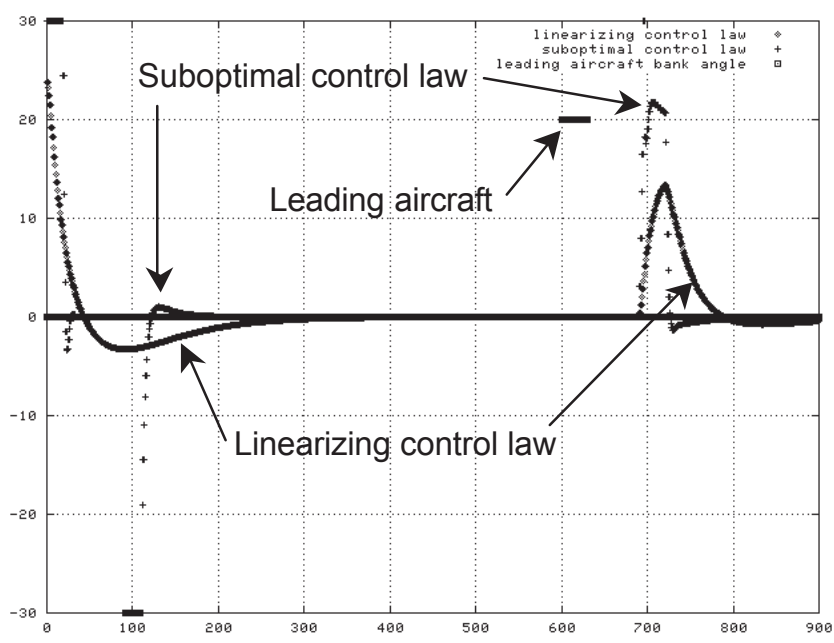

Figure 13 Commanded bank angle (in degrees) as a function of time (in sec)

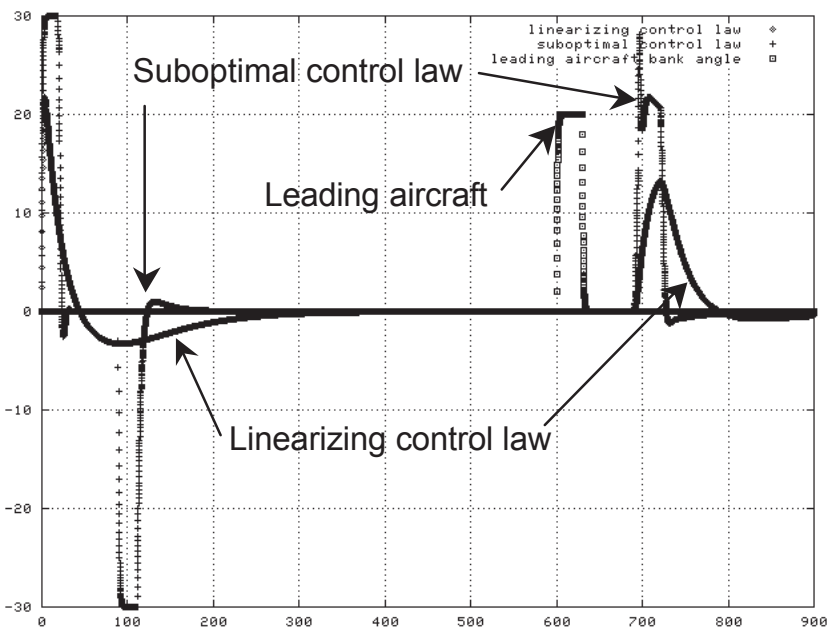

Figure 14 Actual bank angle (in degrees) as a function of time (in sec)

The previous figures illustrate the tendency of the suboptimal control law to zigzag near the final position, where the controlled bank angle chatters back and forth. On the contrary, the bank angles commanded by the linearizing control law are smoother.

\section{CONCLUSION}

In this paper, two control approaches for relative guidance of aircraft have been presented and compared.

A scenario illustrating time delay separation objective has been presented. For the sake of comparison, it has been assumed that the delayed position and velocity of the leading aircraft are available (e.g. broadcasted by the leading aircraft, or correctly estimated by the trailing aircraft).

The approach based on feedback linearizing control requires to estimate the first and the second derivatives of the available 'along track' and 'cross track' distances. This may induce some noise problems. In addition, the degrees of freedom of the control law (i.e. damping ratio and natural frequency) are quite uneasy to settle in order to satisfy operational constraints, like achievable speed and bank angle : this has been done by successive trials.

On the other hand, the approach based on optimal control theory leads to a direct merging control law which tends to generate oscillations around the desired final relative position.

Thus, it appears that a two stage control law could result in a satisfactory design : the suboptimal controller is adapted for merging operations, and generates standard trajectories (i.e. merging with a convergence angle of 45 degrees), whereas the feedback linearizing controller is more suited for maintaining separations to desired values.

From an operational perspective, attention should be paid to the fact that current separation between the two aircraft has not been taken explicitly into account in the design process. It may result in actual separation under the desired value during a transient period, as underlined in the RESULTS AND COMPARISON section. This deserves further studies in order to refine and validate the proposed controllers.

\section{REFERENCES}

1. FAA-Eurocontrol cooperative R\&D action plan 1, Principle of operations for the use of ASAS, version 7.1, june 2001

2. Agelii M., Olausson C., Flight deck smulations of station keeping, ATM 2001 R\&D seminar, Santa Fe, paper no. 17

3. Li S.M., Boskovic J.D., Mehra R.K., Globally stable automatic formation flight control in two dimensions, AIAA Guidance, Navigation and Control Conference. Montreal, August 2001. Paper No. 2001-4046

4. Giulietti F., Pollini L., Innocenti M., Autonomous Formation Flight, IEEE Control Systems Magazine, December 2000

5. Vinken P., Hoffman E., Zeghal K., Influence of Speed and Altitude Profile on the Dynamics of In-trail 
Following Aircraft, AIAA Guidance, Navigation and Control Conference. Denver, Colorado, August 2000. Paper No. 2000-4362

6. Sorensen J.A., Goka T., Analysis of in-trail following dynamics of CDTI-equipped aircraft, Journal of guidance, control and dynamics, Vol. 6, No. 3, pp. 162-169, 1983

7. ICAO, annex 10, volume IV, Surveillance radar and collision avoidance systems, International standards and recommended practices, July 1998

8. Pachter M., D'Azo J.J., Dargan J.L., Automatic formation flight control, Journal of guidance, control and dynamics, Vol. 17, No. 6, pp. 1380-1383, 1994

9. Isidori A., Nonlinear control systems, Springer-Verlag, 1989

10. Bryson A.E., Ho Y.C., Applied optimal control, Hemisphere Publishing corporation, 1975

11. Erzberger H., Lee H.Q., Optimum horizontal guidance technique for aircraft, Journal of aircraft, Vol. 8, No. 2, pp. 95-101, 1971

12. Shahzad M., Contribution à l'automatisation $d u$ guidage relatif des aéronefs : gestion des séparations et de la convergence, thèse de doctorat, LAAS du CNRS et ENAC, 2000 